\title{
Analysis of Major Components Contained in Bis-GMA Monomer
}

\author{
Ayumi OHSAKI and Yohji IMAI \\ Institute of Biomaterials and Bioengineering, \\ Tokyo Medical and Dental University, 2-3-10, \\ Kanda-Surugadai, Chiyoda-ku,Tokyo, 101-0062, Japan
}

Received July 14, 1999/Accepted September 13, 1999

\begin{abstract}
The major components contained in commercial Bis-GMA monomer were isolated by thin layer chromatography (TLC) and identified by NMR and high resolution mass spectroscopy. In addition to the two major components already known (Bis-GMA and Iso-bis-GMA), an unknown hydrophilic third major component was isolated and identified as 2,2-[4-(2-hydroxy-3methacryloyloxy-1-propoxy)-4'-(2,3-dihydroxy-1-propoxy)]diphenylpropane. This compound was designated as BIS-GMA-H, because it has a structure of Bis-GMA with one of which methacrylic ester bond hydrolyzed.
\end{abstract}

Key words : Bis-GMA, HPLC, NMR

\section{INTRODUCTION}

Bisphenol A glycidyl methacrylate, or Bis-GMA, has been widely used in dental composites and sealants. However, the estrogenic effects of Bis-GMA-based resins have recently raised controversy and concern about the safety of the monomer leached out of these materials ${ }^{1-3)}$. The leached components from resins have generally been analyzed by high performance liquid chromatography (HPLC). Although the chromatogram of commercially available Bis-GMA exhibits four major peaks and many minor peaks at different retention times as shown in Fig. 1, only one peak has usually been assigned to Bis-GMA monomer. It seems that two big peaks at the retention times of $17.3 \mathrm{~min}$ and $17.0 \mathrm{~min}$ in Fig. 1 have been combined and designated as BisGMA. Meanwhile, the third major peak with a retention time of 7.9 min was designated "Unknown I" in a recent paper". The "Unknown I" substance has been observed in all of six Bis-GMA-based sealants tested ${ }^{2)}$.

The third component seems to have drawn little attention up to the present time. However, it is very important from the viewpoint of leaching characteristics and safety issues, because it is supposed to be more hydrophilic, as judged from its shorter retention time on a reverse-phase ODS column, than the other three components and may therefore leach out more easily into an aqueous environment. While the structures of the two major components have already been determined ${ }^{4)}$, the structure of the third component remains undetermined. Thus the purpose of this investigation was to identify the third major component contained in the so-called Bis-GMA monomer. 


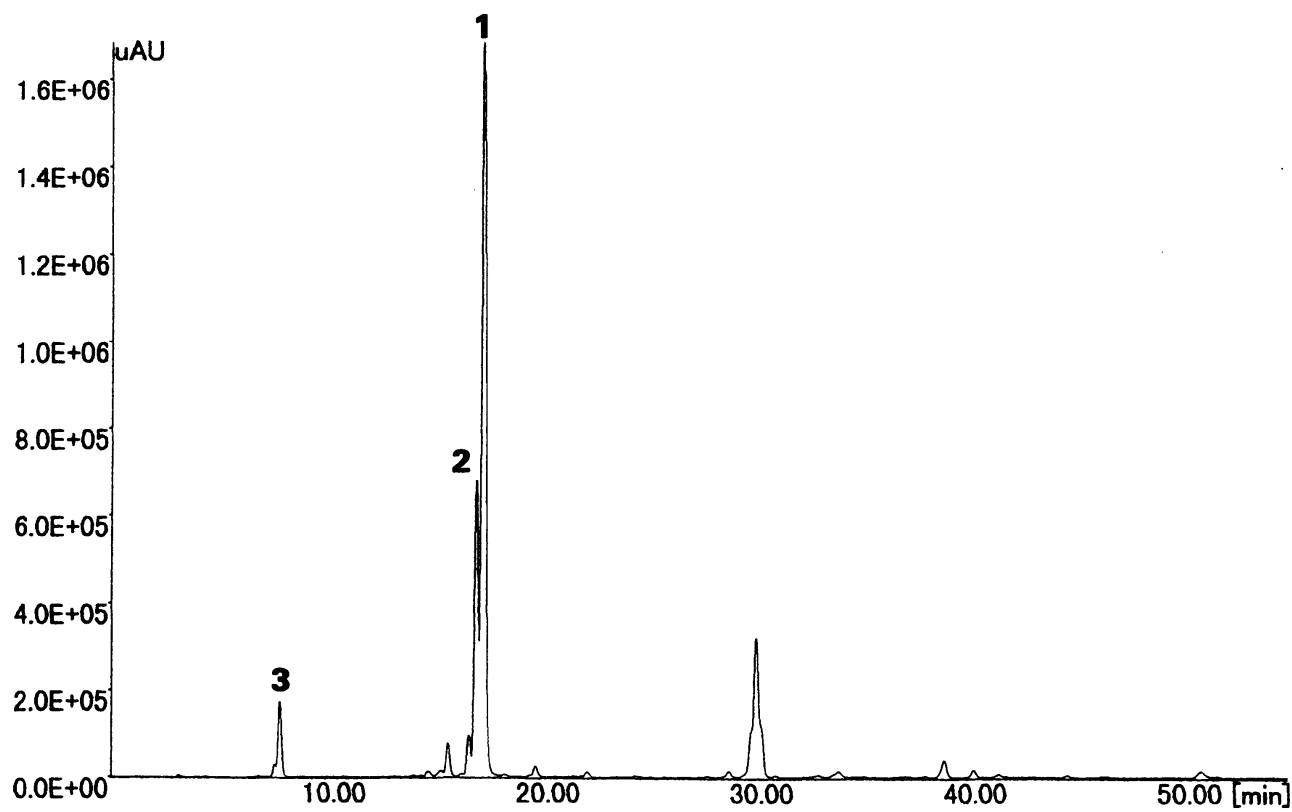

Fig. 1 Chromatogram of commercial Bis-GMA monomer. HPLC analysis was performed using a flow rate of $1 \mathrm{~mL} / \mathrm{min}$ for an acetonitrile/water gradient programmed from $50 / 50 \%$ to $100 \%$ in $55 \mathrm{~min}$.

\section{MATERIALS AND METHODS}

\section{Materials}

Bis-GMA used in this study was D-GMA, lot No.0601K from Shin-Nakamura Chemical Co., Wakayama, Japan.

\section{HPLC analysis}

HPLC analysis was performed using a JASCO system (GULLIVER 1500, JASCO, Tokyo, Japan), equipped with a CAPCELL PAK $\mathrm{C}_{18}$ column (UG120, $4.6 \mathrm{~mm} \times 250$ $\mathrm{mm}$, Shiseido, Tokyo, Japan) and a diode array detector (MD-1510) (detection at $\lambda=$ $230 \mathrm{~nm}$ ) and at a flow rate of $1 \mathrm{~mL} / \mathrm{min}$ at $40^{\circ} \mathrm{C}$. Mixtures of acetonitrile (CicaMERCK, HPLC grade, Kanto Chemical Co. Tokyo, Japan) and water were used as the solvent system, with a gradient starting at $50 \%$ acetonitrile and increasing to $100 \%$ within $55 \mathrm{~min}$.

\section{Isolation of major three components}

To isolate the components, thin layer chromatography (TLC) (methanol/ chloroform: $5 / 95)$ was carried out on TLC plates coated with silica gel $(0.25$ or $0.5 \mathrm{~mm})$ containing a fluorescent indicator $\left(200 \mathrm{~mm} \times 200 \mathrm{~mm}, 60 \mathrm{~F}_{254}\right.$, Kanto Chemical Co. Tokyo, Japan) and visualized under a UV lamp. Analytically, TLC plates were dipped in a solution of $20 \%$ phosphomolybdic acid in ethanol followed by heating. The third 
component (3) obtained was purified further by isocratic HPLC on a Waters radialpack cartridge $(8 \mathrm{NVC} 184 \mu, 8 \mathrm{~mm} \times 100 \mathrm{~mm}$, Japan Waters, Tokyo, Japan) using a solvent (acetonitrile/water: 45/55) at a flow rate of $2 \mathrm{~mL} / \mathrm{min}$. The retention time of (3) was $3.4 \mathrm{~min}$.

\section{Analyses of the components isolated}

${ }^{1} \mathrm{H}$ and ${ }^{13} \mathrm{C}$ NMR spectra were recorded in $\mathrm{CDCl}_{3}$ containing $0.05 \%$ tetramethysilane (TMS) on a spectrometer (JEOL, ALPHA 500, JEOL, Tokyo, Japan) operating at 500 $\mathrm{MHz}$ and $125 \mathrm{MHz}$, respectively. Chemical shifts were referenced internally to ${ }^{13} \mathrm{C}$ resonance in $\mathrm{CDCl}_{3}(77.0 \mathrm{ppm})$ and to TMS for ${ }^{1} \mathrm{H}(0.00 \mathrm{ppm})$. ${ }^{1} \mathrm{H}$ resonance was assigned by a combination of one-dimensional and two-dimensional methods; ${ }^{1} \mathrm{H}-{ }^{1} \mathrm{H}$ COSY (Correlation spectroscopy) ${ }^{5,6)},{ }^{1} \mathrm{H}^{-13} \mathrm{C} \mathrm{COSY}^{6}$ ), and HMBC ( ${ }^{1} \mathrm{H}-$ Detected Multiplebond Heteronuclear Multiple Quantum Coherrence Spectrum) $)^{7}$.

High resolution mass spectra (HRMS) were recorded on a double focusing high resolution mass spectrometer (JMS-AX505H, JEOL, Tokyo, Japan). Electron impact ionization (EI) was applied with an electron energy of $70 \mathrm{eV}$.

\section{RESULTS AND DISCUSSION}

Fig. 1 shows a typical chromatogram of the Bis-GMA monomer used. It exhibits four major peaks and many minor peaks at different retention times. The first major peak (1) was assigned to so-called Bis-GMA. The second peak (2) close to Bis-GMA was assigned to Iso-bis-GMA ${ }^{4)}$, an isomer of Bis-GMA. The structures of the two Bis-GMAs were identified by NMR analysis as shown in Fig. 2. They agree with those reported in the literature ${ }^{4)}$.

The third compound corresponding to the retention time of $7.9 \mathrm{~min}$ (3) in Fig. 1 was obtained as a colorless oil and its HRMS produced an $\mathrm{m} / \mathrm{z}$ of $444.2135 \mathrm{M}^{+}$, suggesting $\mathrm{C}_{25} \mathrm{H}_{32} \mathrm{O}_{7}$ (formula mass, 444.2148).

Fig. 3 shows the NMR data obtained. The ${ }^{1} \mathrm{H}$ spectrum showed the presence of two kinds of tertiary methyl group at $\delta 1.96 \mathrm{ppm}(3 \mathrm{H})$ and $\delta 1.63 \mathrm{ppm} .(6 \mathrm{H})$, and the presence of aromatic proton signals with ortho-coupling constant $(J=8.6 \mathrm{~Hz})$ at $\delta$ $6.81 \mathrm{ppm}(4 \mathrm{H})$ and $\delta 7.14 \mathrm{ppm}(4 \mathrm{H})$, and broad singlet signals of exomethylene protons at $\delta 5.61 \mathrm{ppm}(1 \mathrm{H})$ and $\delta 6.14 \mathrm{ppm}(1 \mathrm{H})$, respectively. All of the remaining protons were revealed to be attached to the oxygen-bearing carbon, since they were observed at $\delta$ 4.0-5.0 ppm. In the ${ }^{13} \mathrm{C} N M R$ spectrum, the chemical shifts were similar to those of Bis-GMA (1) except for three oxygenated carbon signals at $\delta 63.70$ ppm (triplet), $\delta 69.22 \mathrm{ppm}$ (triplet), and $\delta 70.35 \mathrm{ppm}$ (doublet). Based on these data and the result of extensive NMR examinations (distortionless enhancement by polarization transfer ${ }^{5)},{ }^{1} \mathrm{H}-{ }^{1} \mathrm{H}$ COSY,${ }^{1} \mathrm{H}^{-13} \mathrm{C} \mathrm{COSY}$, and $\left.\mathrm{HMBC}\right)$, the structure of the third component (3) was established as 2,2-[4-(2-hydroxy-3-methacryloyloxy-1propoxy)-4'-(2,3-dihydroxy-1-propoxy)]diphenylpropane, designated as Bis-GMA-H, because it is a partially hydrolyzed Bis-GMA. The content of Bis-GMA-H was 5.0 wt\% in the Bis-GMA used in the present study. 


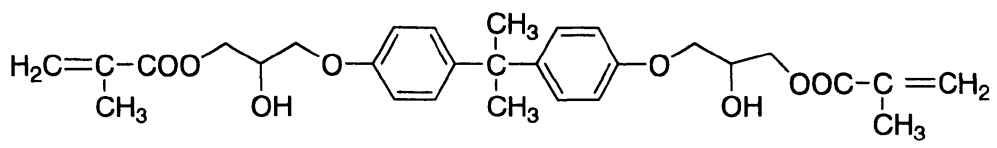

Bis-GMA (1)
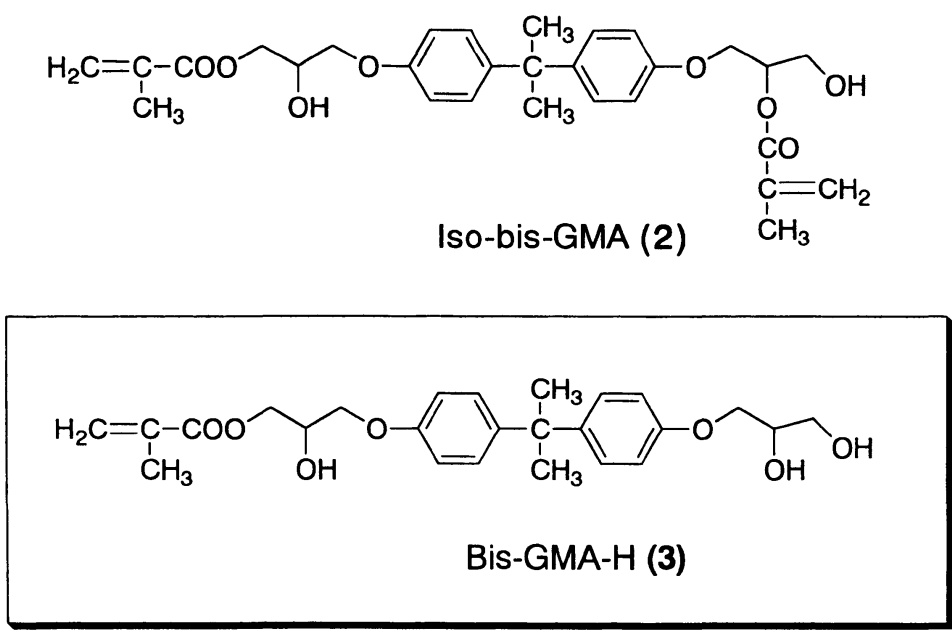

Fig. 2 Structures of Bis-GMAs (1-3)

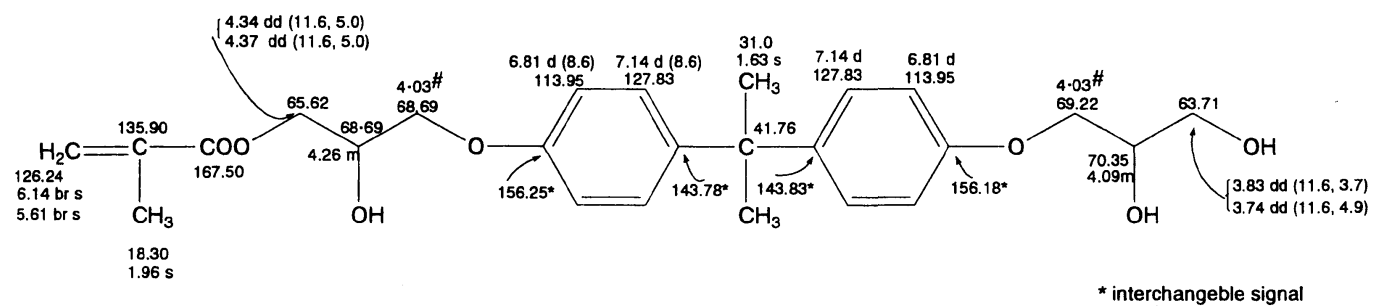

Fig. $3{ }^{1} \mathrm{H}$ and ${ }^{13} \mathrm{C}$ NMR data of Bis-GMA-H (3)

Bis-GMA-H has a retention time very close to that of bisphenol A (BPA), which is a substance of recent controversy in Bis-GMA-based resins ${ }^{1-3)}$, under a certain HPLC condition as suggested in a recent paper ${ }^{2}$; "Unknown I" (Bis-GMA-H) and BPA were reported to have retention times of 2.32 and $2.05 \mathrm{~min}$, respectively. Moreover, an unseparated peak for Bis-GMA-H and BPA was observed at the retention time of $4.0 \mathrm{~min}$, for example, in the HPLC system used here when HPLC analysis was performed using a flow rate of $1 \mathrm{~mL} / \mathrm{min}$ for an acetonitrile/water gradient programmed from $70 / 30 \%$ to $100 \%$ in $10 \mathrm{~min}$. This suggests that the peak for Bis-GMA-H may possibly be misunderstood as that for BPA under a certain liquid chromatography 
condition. The extremely high BPA contents of composite resins and a sealant reported by Olea and colleagues ${ }^{1)}$ may probably be examples of this; regarding the curiosity of their HPLC data, one of the present authors has already commented that the data relevant to HPLC analysis presented by Olea et al. are not reliable and that these data should be corrected or withdrawn ${ }^{8)}$.

In view of the ease of leaching of Bis-GMA-H into an aqueous environment and its presence in all Bis-GMA-based resins ${ }^{9)}$, more attention should be paid to the third component contained in commercial Bis-GMA monomers in evaluating its biological effects. Moreover, in HPLC analysis, care should be taken to establish the condition necessary to clearly separate the peaks for BPA and Bis-GMA-H. Identification of the fourth major component remains undetermined, but is now in progress and the result will be reported in the near future.

\section{CONCLUSION}

The third major component contained in a commercial Bis-GMA monomer was isolated by TLC and identified by NMR and HRMS as 2,2-[4-(2-hydroxy-3-methacryloyloxy-1-propoxy)-4'-(2,3-dihydroxy-1-propoxy)]diphenylpropane (Bis-GMA-H).

\section{REFERENCES}

1) Olea, N., Pulgar, R., Pérez, P., Olea-Serrano, F., Ravis, A., Novillo-Fertrell, A., Pedraza, V., Soto, A. M. and Sonnenschein, C.: Estrogenicity of resin-based composites and sealants used in dentistry, Environ Health Perspect $104: 298-305,1996$.

2) Nathanson, D., Lertpitayakun, P., Lamkin, M. S., Edalatpour, M. and Chou, L. L.: In vitro elution of leachable components from dental sealants, JADA $128: 1517-1523,1997$.

3) Söderholm, K.-J. and Mariotti, A.: Bis-GMA-based resins in dentistry: are they safe?, JADA 130 : 201-209, 1999.

4) Vankerckhoven, H., Lambrechts, P., Van Beylen, M. and Vanherle, G.: Characterization of composite resins by NMR and TEM, J Dent Res $60: 1957-1965,1981$.

5) Derome, A. E.: Modern NMR techniques for chemistry research (Organic chemistry series, volume 6), Pergamon Press, Oxford, 1987.

6) Kusumi, T., Iwashita, T. and Naoki, H.: Superconducting FT-NMR, Kodansha, Tokyo, 1986.

7) Summers, M.F., Marzilli, L. G. and Bax, A.: Complete ${ }^{1} \mathrm{H}$ and ${ }^{13} \mathrm{C}$ assignments of coenzyme $\mathrm{B}_{12}$ through the use of new two-dimensional NMR experiments, $J$ Am Chem Soc $108: 4285-4294,1986$.

8) Imai, Y.: Comments on the paper "Estrogenicity of resin-based composites and sealants used in dentistry" by Olea et al. (1), Environ Health Perspect 107 : A290, 1999.

9) Imai, Y., Watanabe, M. and Ohsaki, A.: Analysis of Bis-GMA monomer by high performance liquid chromatography, $J J$ Dent Mater 18, Special Issue 34, 130, 1999. 